$$
\begin{aligned}
& \text { رخانكوز }
\end{aligned}
$$

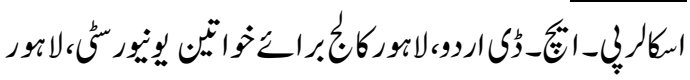

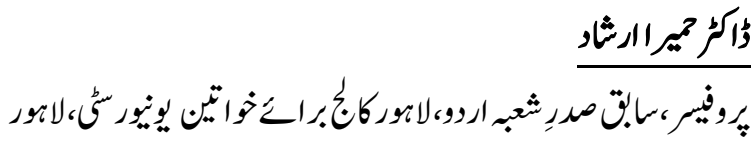

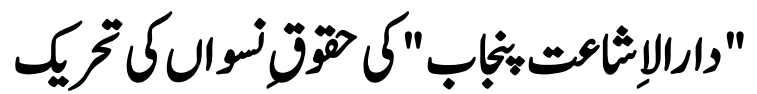

\title{
Rukhsana Kausar
}

Scholar Ph.D Urdu, Lahore College for Women University, Lahore.

\section{Dr. Humaira Irshad}

Professor, Ex. Head of Departnemt of Urdu, Lahore College for Women University, Lahore.

\section{Movement Launched by Dar-ul-Ishait-i-Punjab for Women's Rights}

Survival of a nation lies in equal contribution of men and women in social, economic and cultural progress and prosperity. Women were deprived of their fundamental rights. As a reaction, women initiated a movement called Feminism for their rights in Europe in the nineteenth century. Molvi Mumtaz Ali started a publishing firm, Darul-Ishaiat-i-Punjab at Lahore in 1898. Its publications especially weekly magazine "Tehzeeb-un-Niswan" played a vital role in the movement of feminism in the sub-continent. It inspired women to write articles on their various issues and rights. Their writings were published in Tahzib-un-Niswan. It motivated women to contribute writing journals, articles, novels, housekeeping manuals, cook books, books of etiquette, prose and poetry.

Keywords: Feminism, Publishing Firm, Publications, Inspiration, Contributions, Articles, Women, Rights.

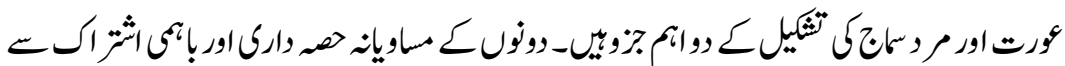

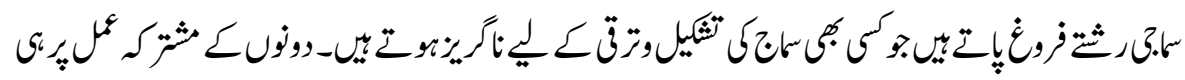

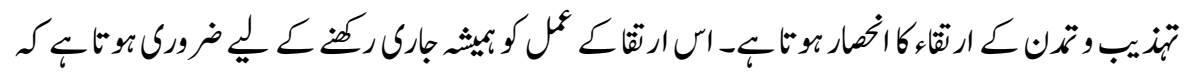




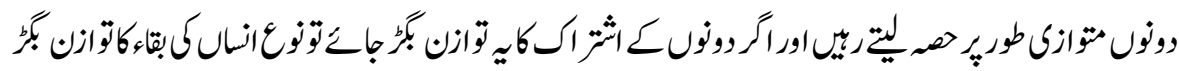

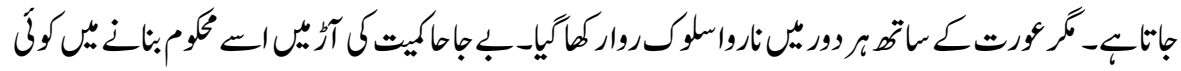

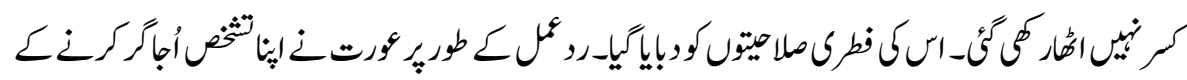

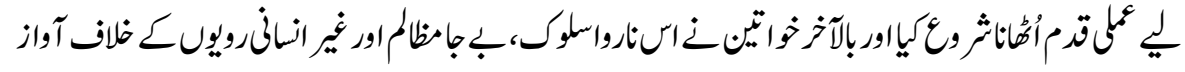

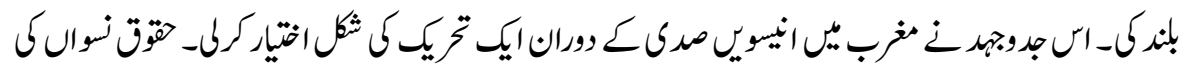

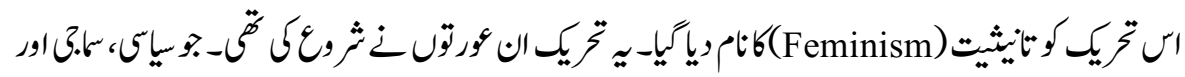

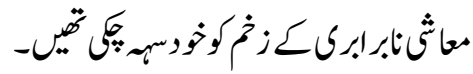

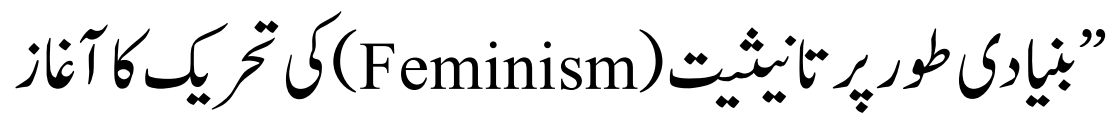

لورب* وال النان:

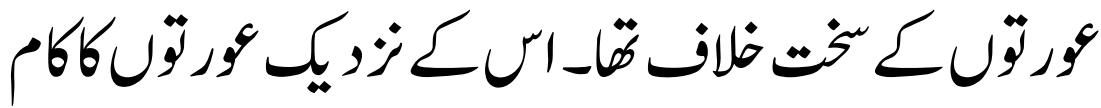

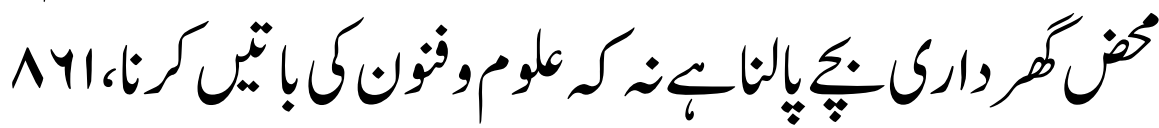

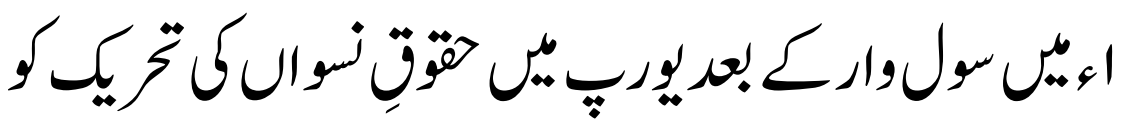
צ و

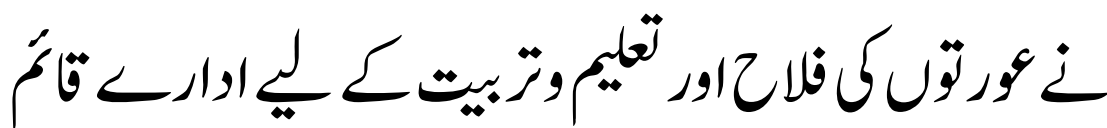

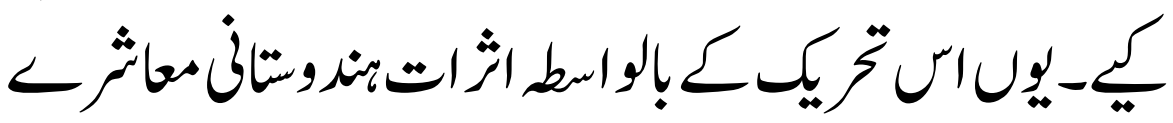
(1) 66 - 
ISSN (Print): 2709-9636 | ISSN (Online): 2709-9644

Volume 2, 2021(Issue III, July to September)

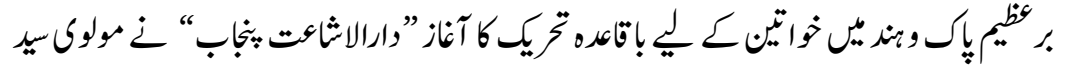

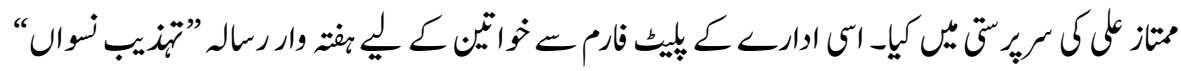

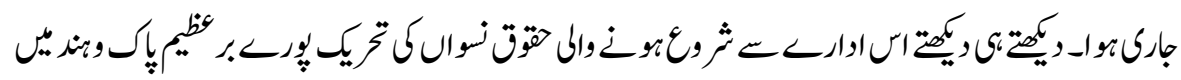

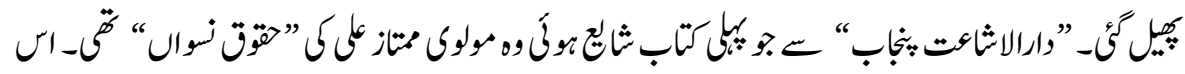

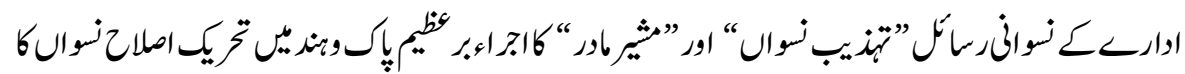

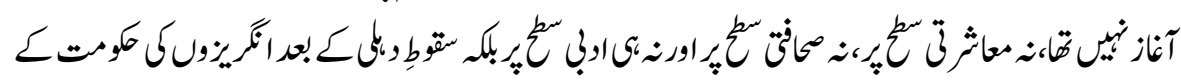

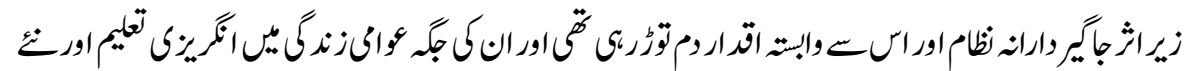

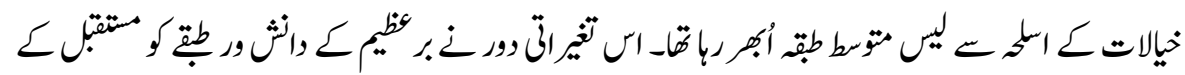

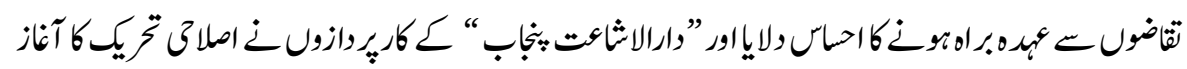

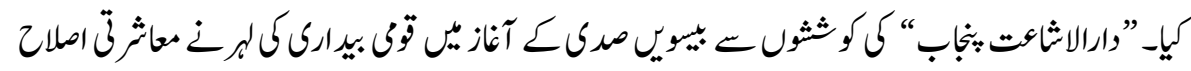

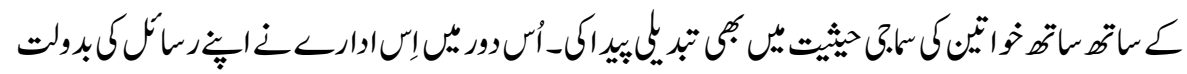

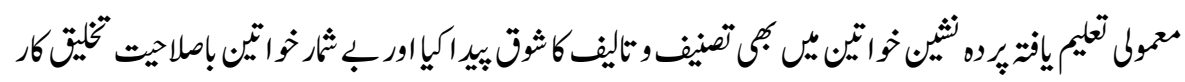

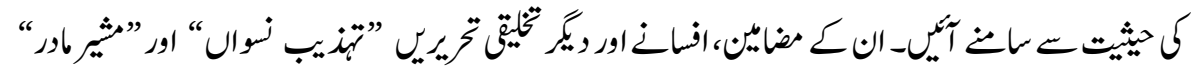

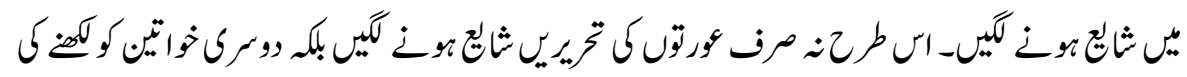

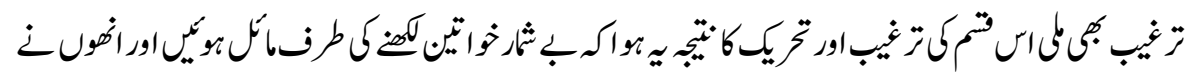

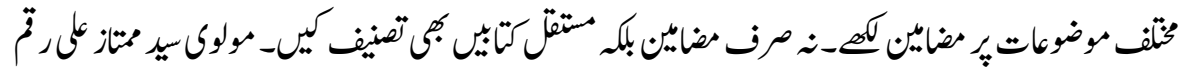

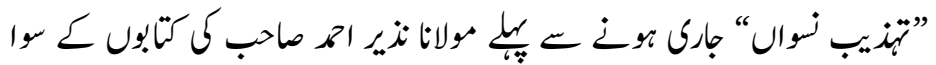

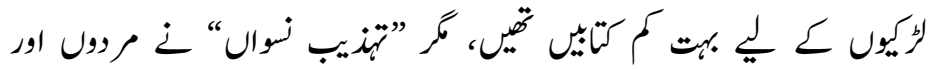

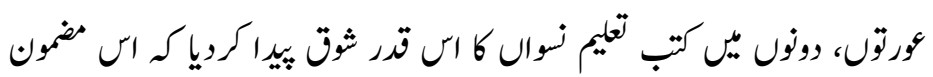

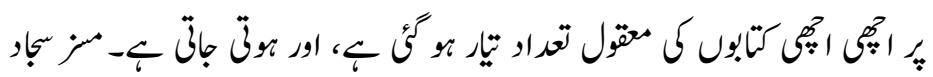

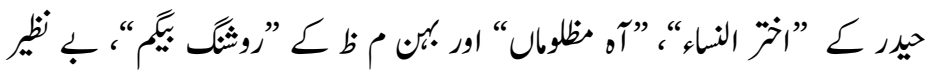

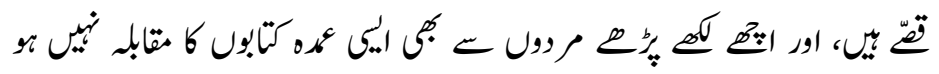


ISSN (Print): 2709-9636 | ISSN (Online): 2709-9644

Volume 2, 2021(Issue III, July to September)

اخذ تخيقي مجله

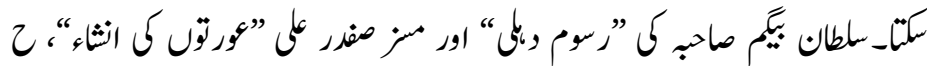

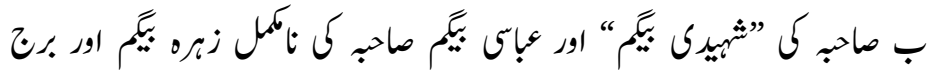

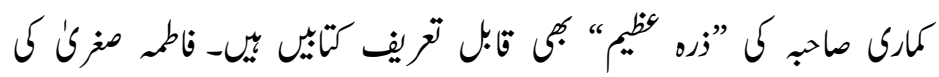

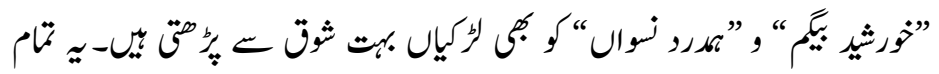

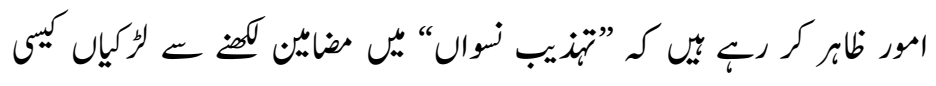

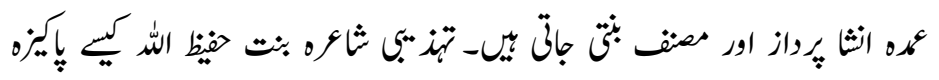

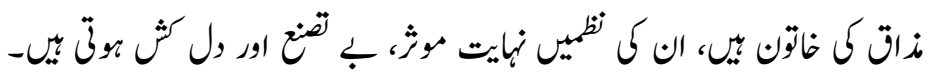

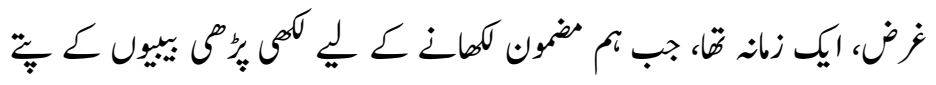

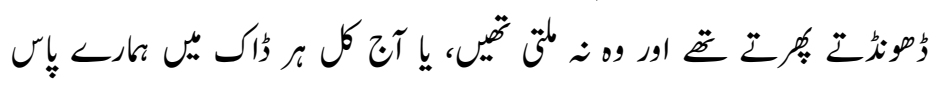

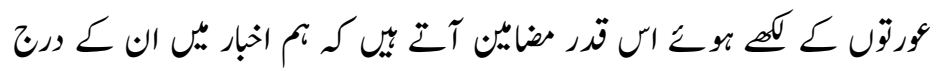

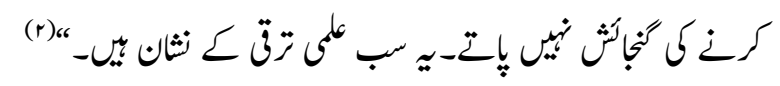

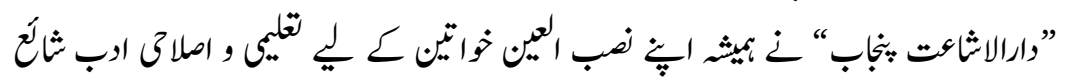

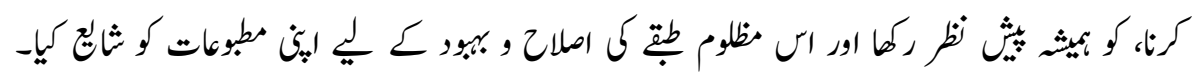

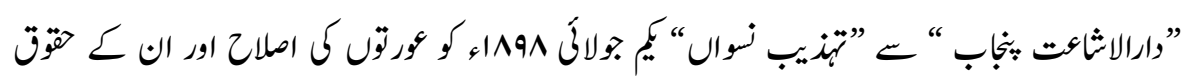

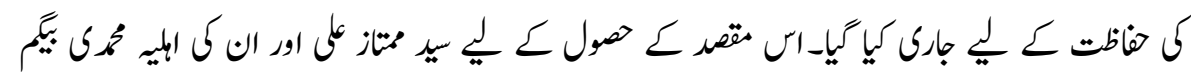

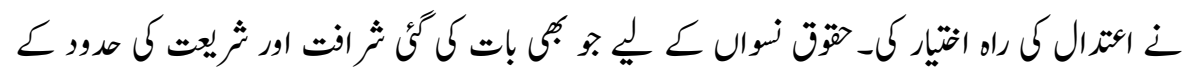

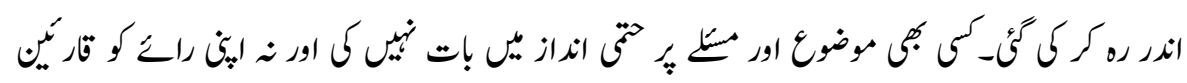

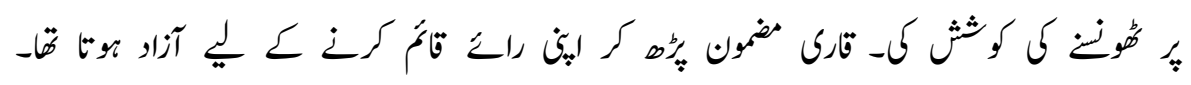

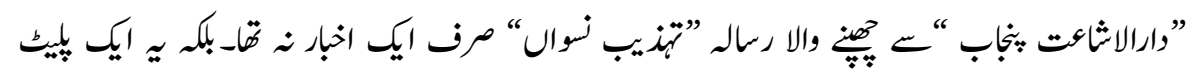

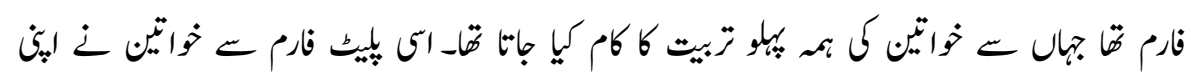

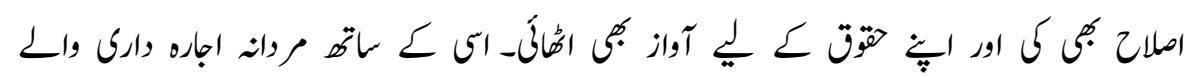

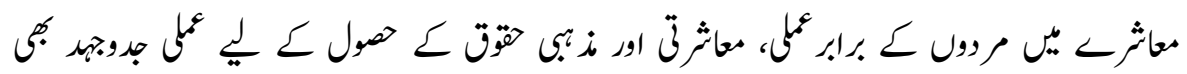

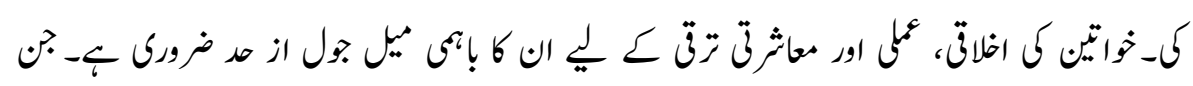




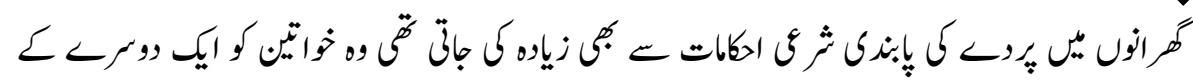

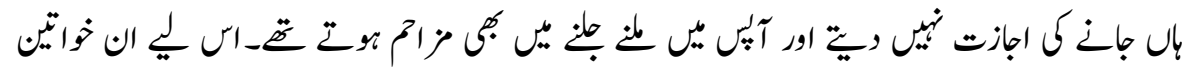

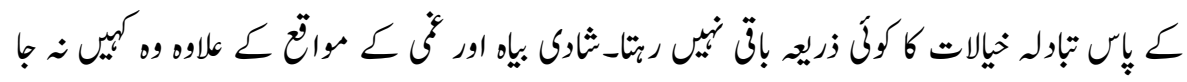

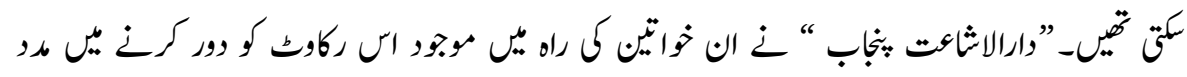

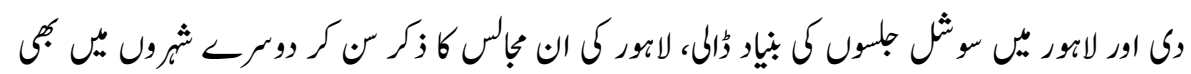

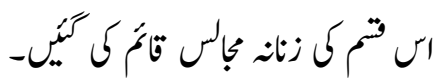

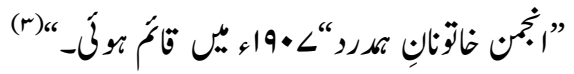

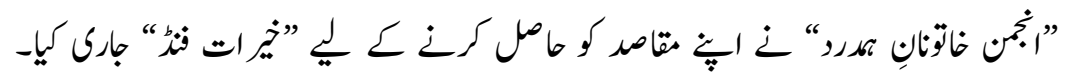

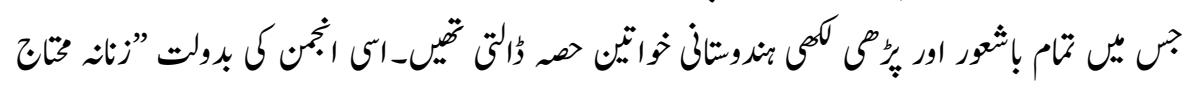

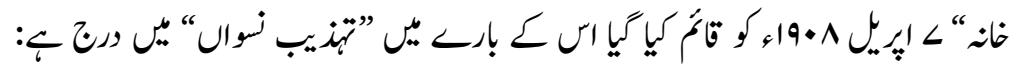

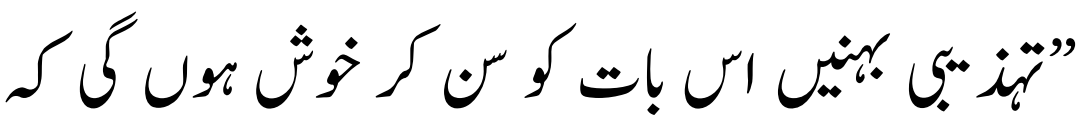

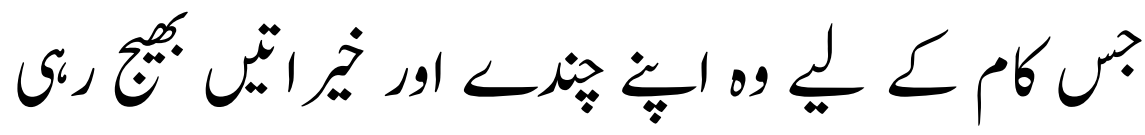

$(r)$ 6

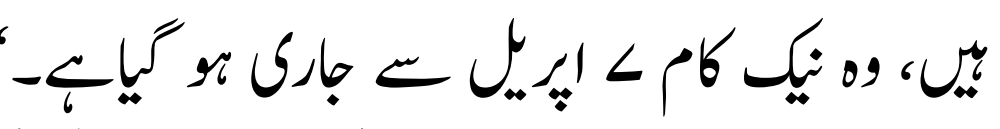

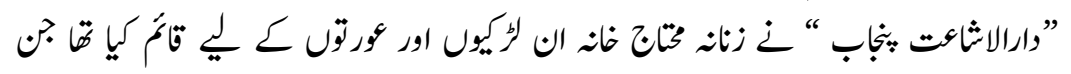

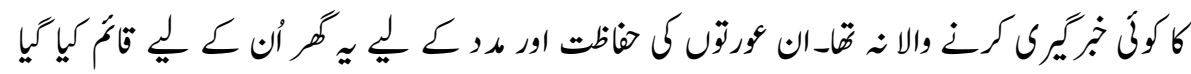

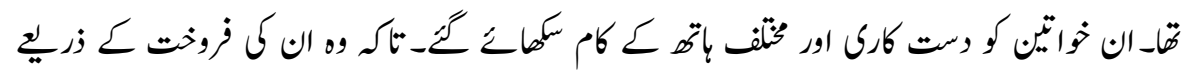

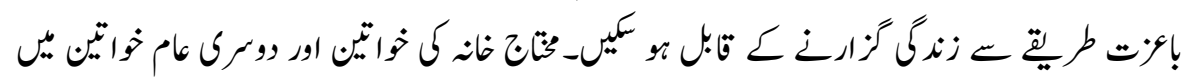

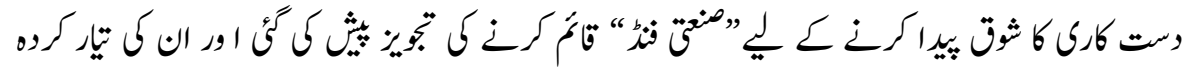

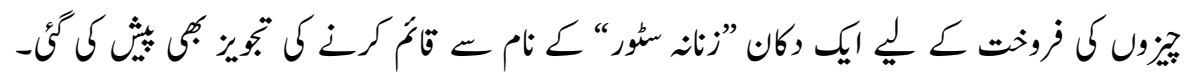

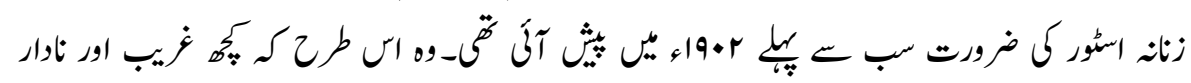

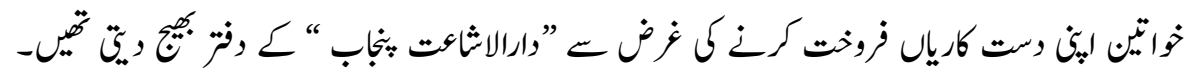




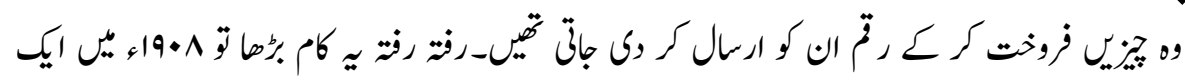

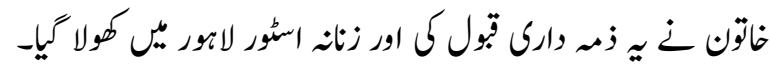

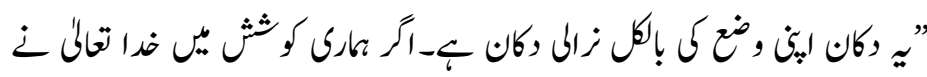

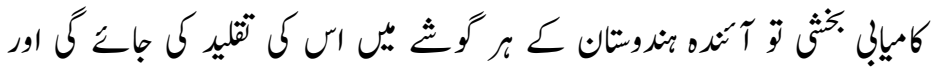

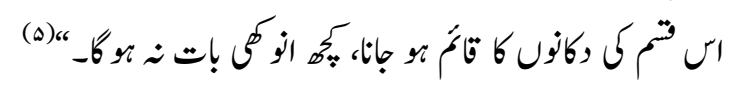

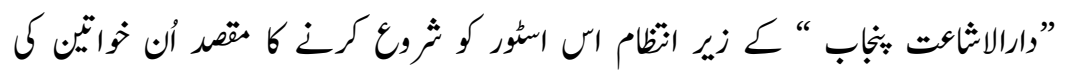

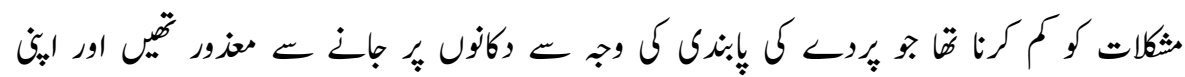

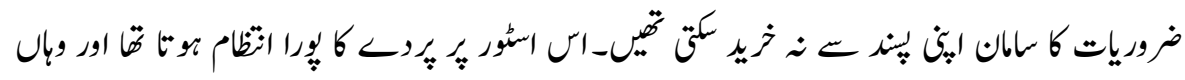

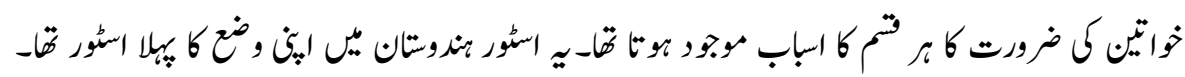

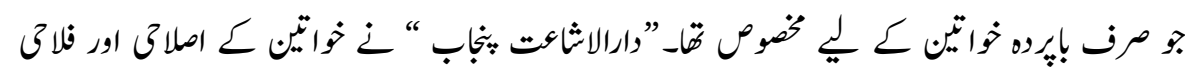

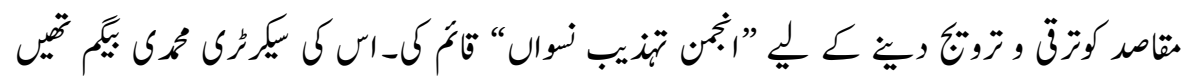

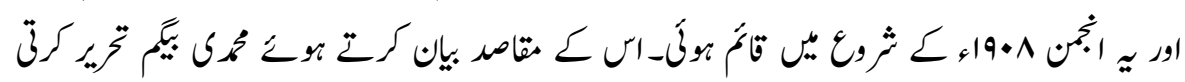

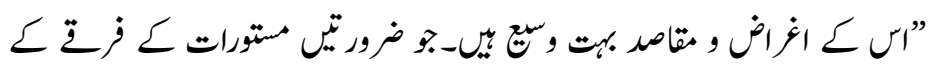

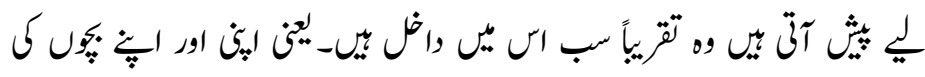

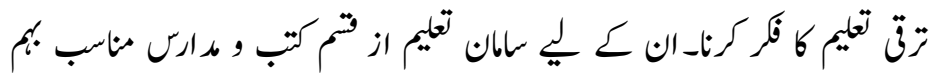

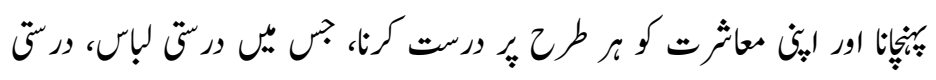

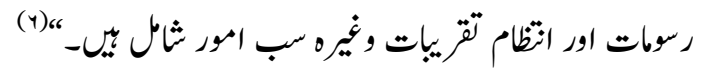

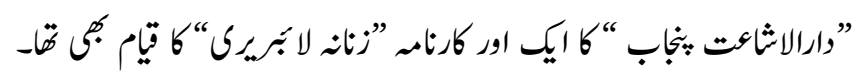

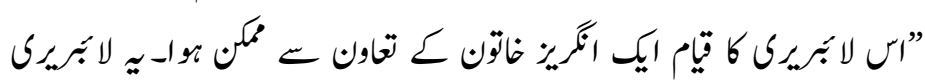

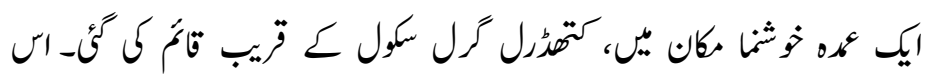

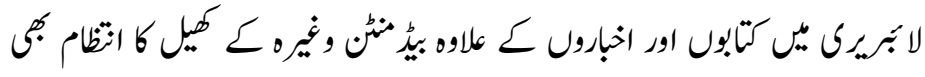


ISSN (Print): 2709-9636 | ISSN (Online): 2709-9644

Volume 2, 2021(Issue III, July to September)

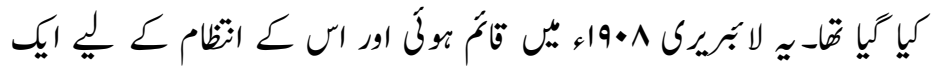

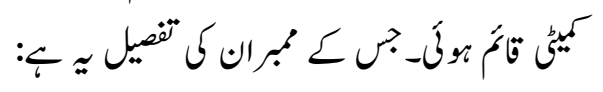

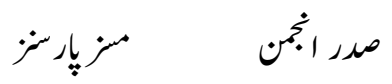

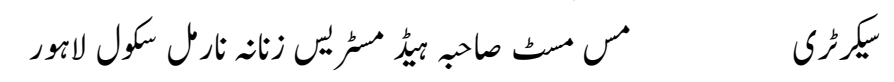

(c)، مبران

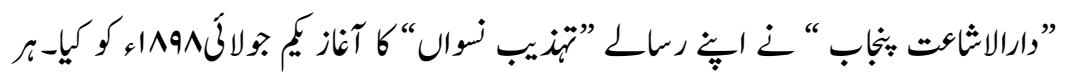

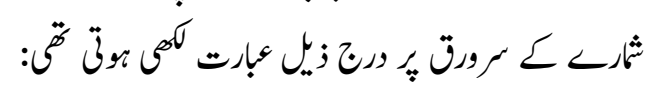

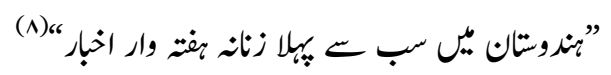

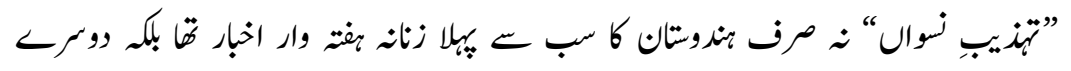

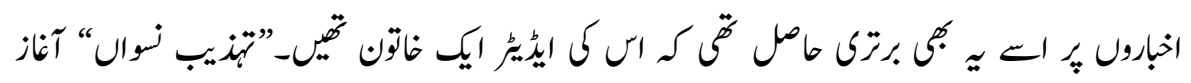

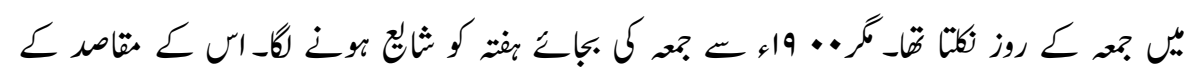

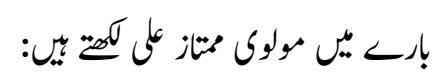

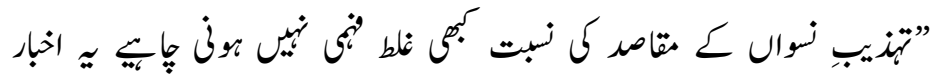

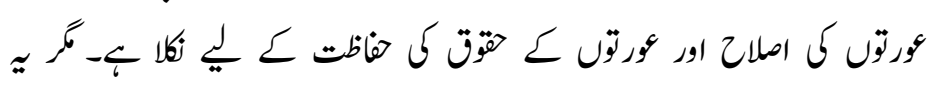

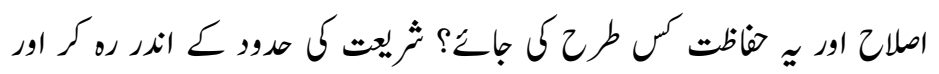

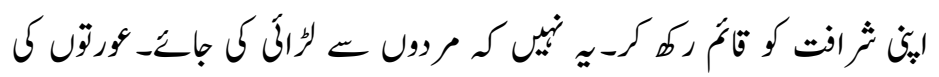

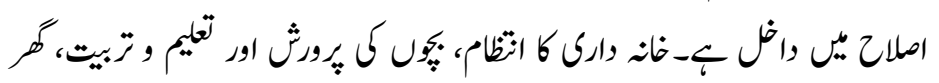

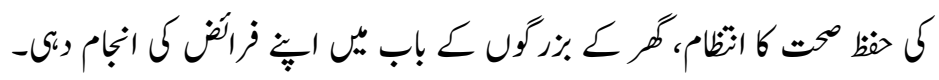

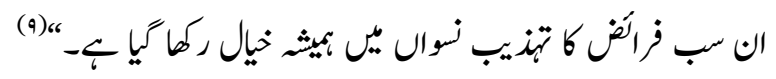

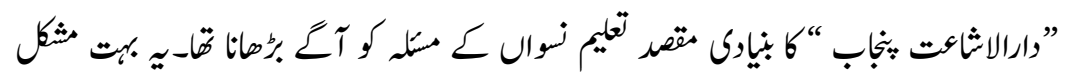

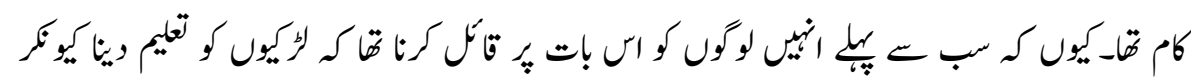

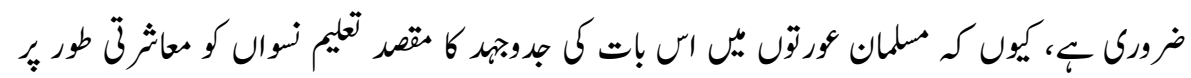

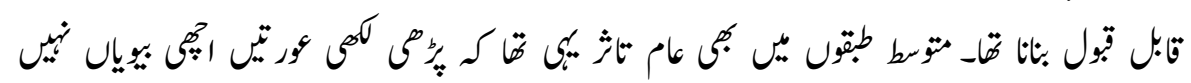


ISSN (Print): 2709-9636 | ISSN (Online): 2709-9644

Volume 2, 2021(Issue III, July to September)

اخذ تخيقي مجله

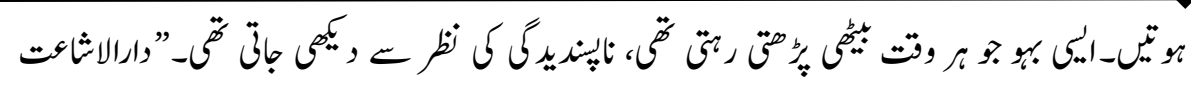

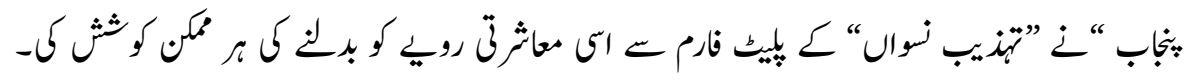

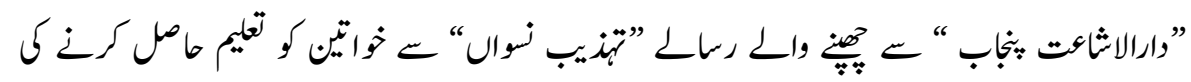

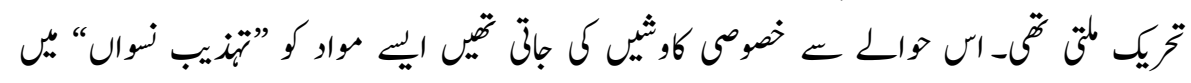

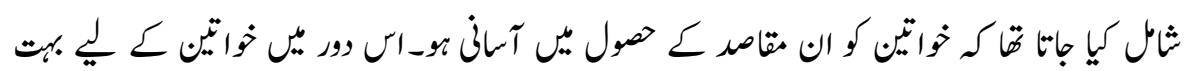

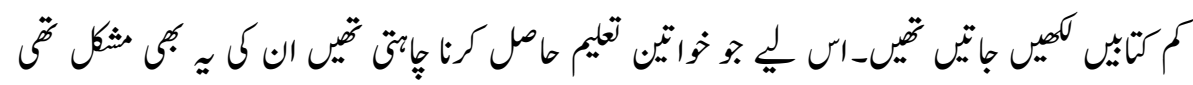

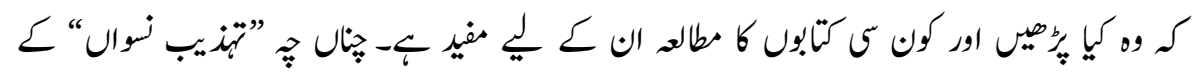

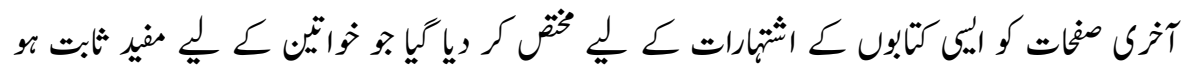

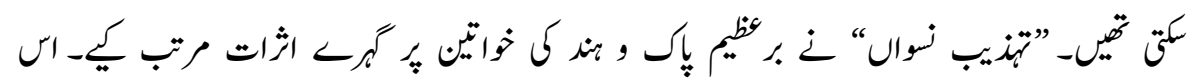

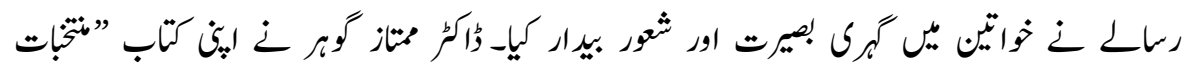

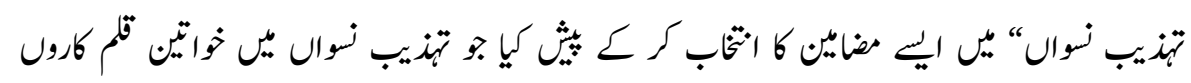

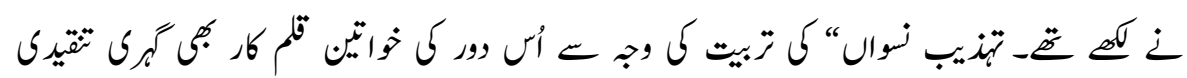

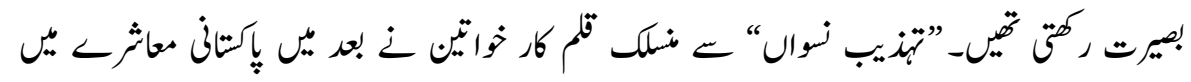

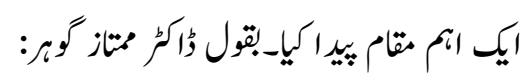

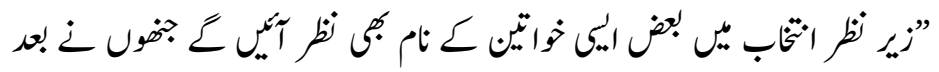

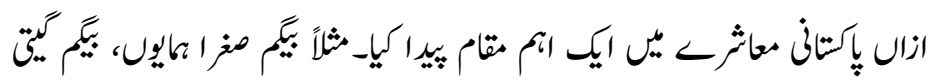

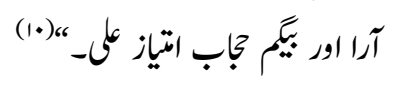

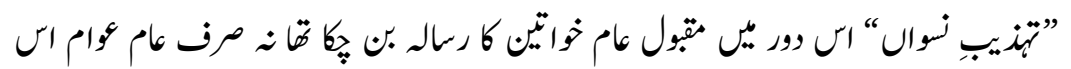

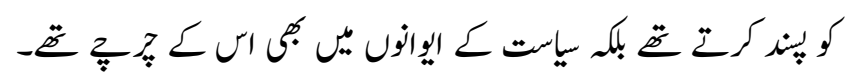

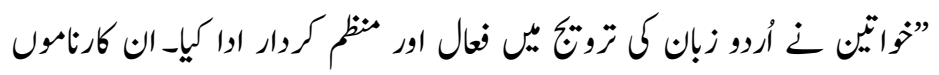

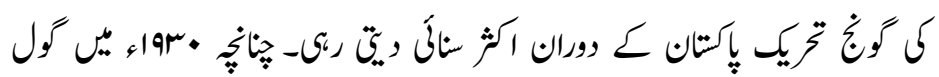

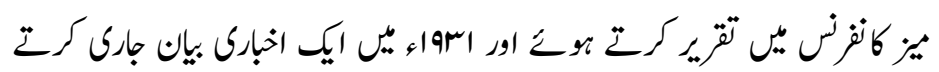


ISSN (Print): 2709-9636 | ISSN (Online): 2709-9644

Volume 2, 2021(Issue III, July to September)

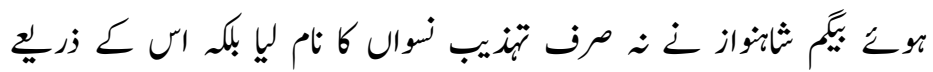

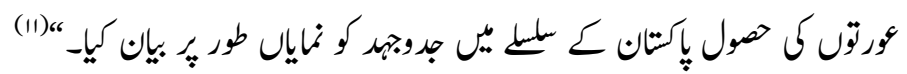

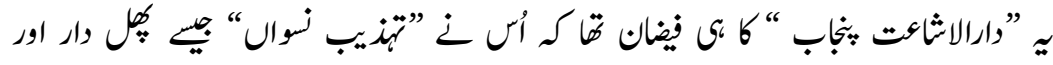

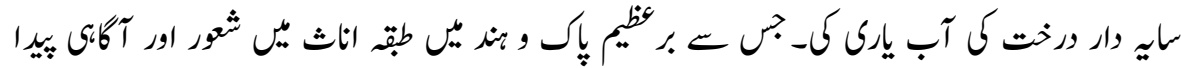

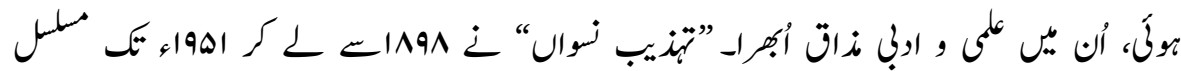

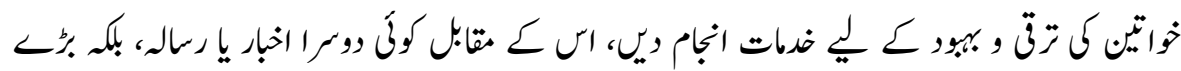

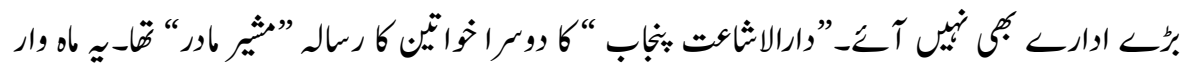

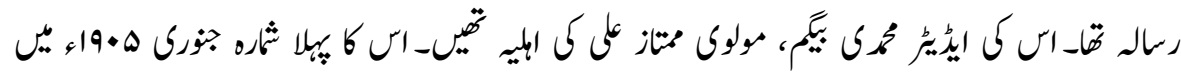

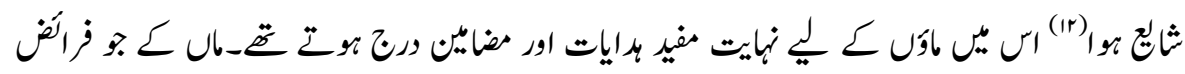

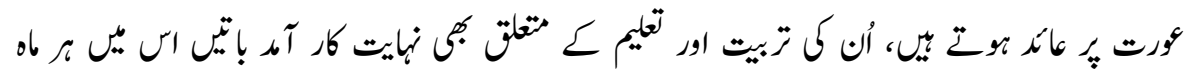

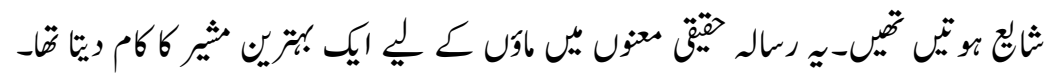

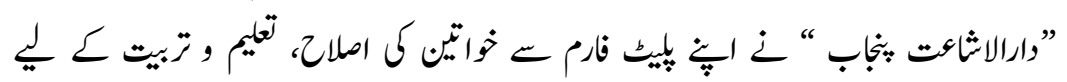

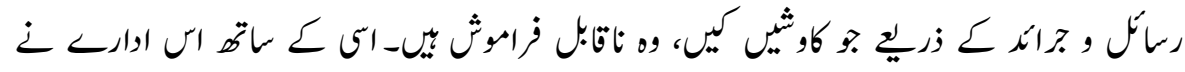

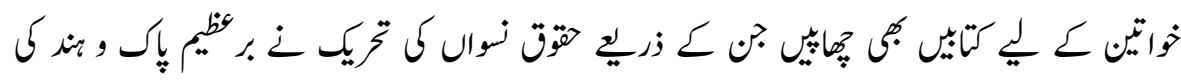

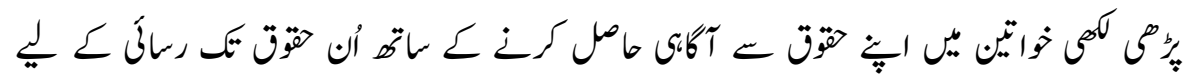

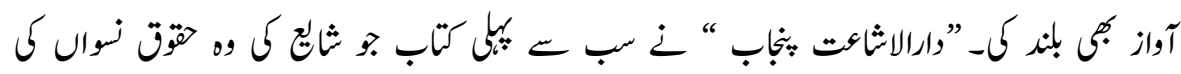

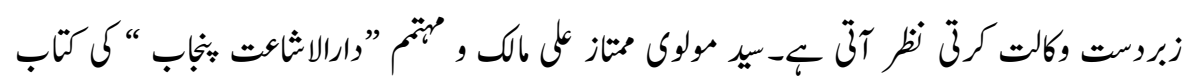

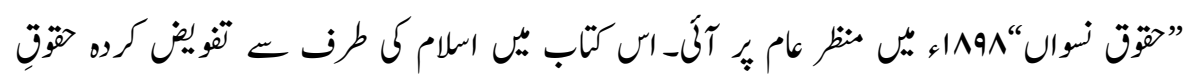

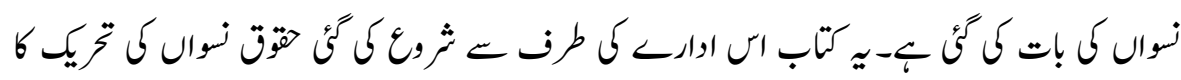

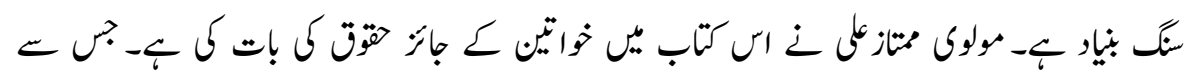

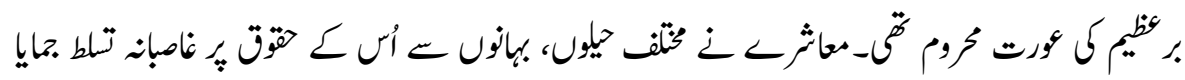

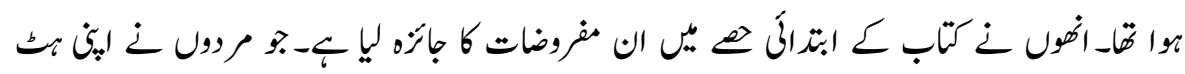

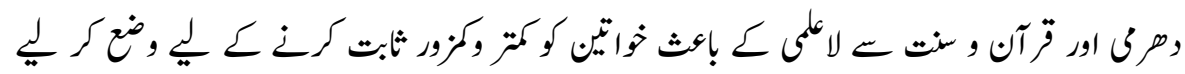


ISSN (Print): 2709-9636 | ISSN (Online): 2709-9644

Volume 2, 2021(Issue III, July to September)

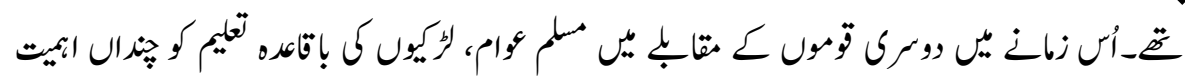

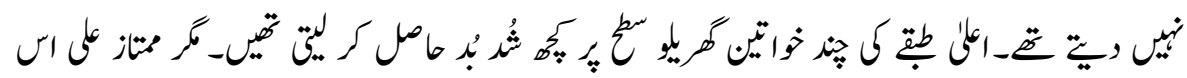

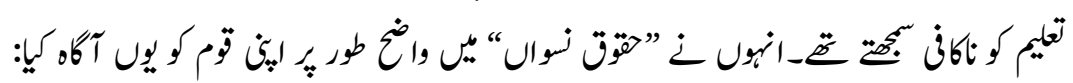

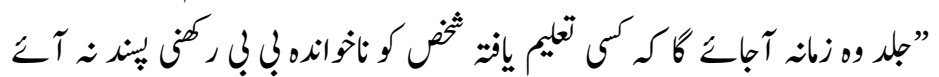

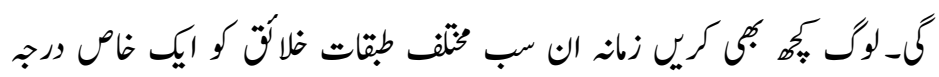

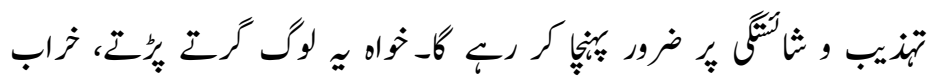

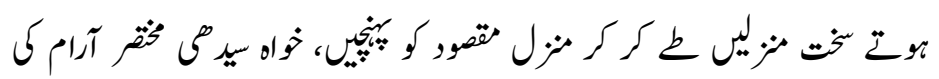

(Ir)، נום (1)

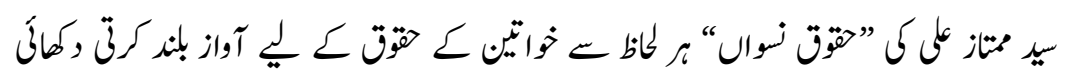

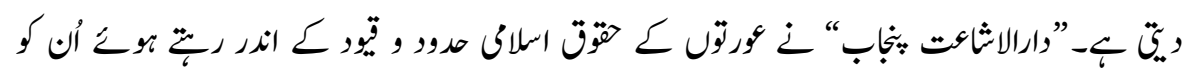

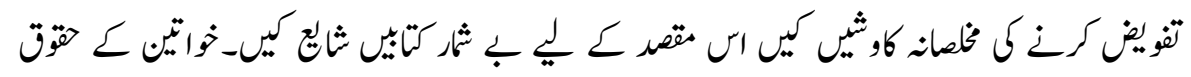

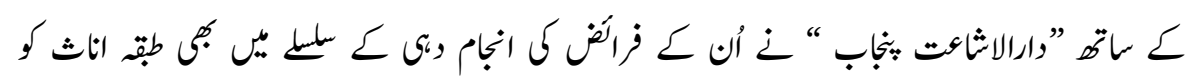

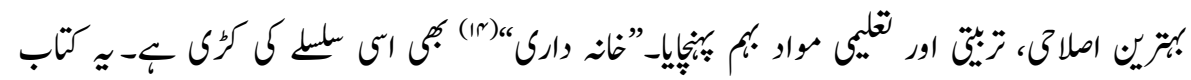

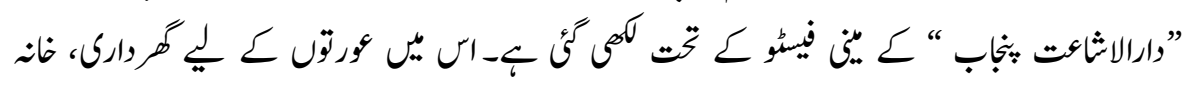

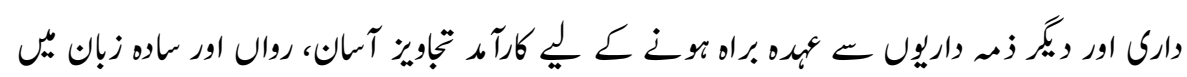

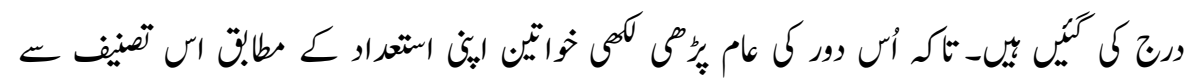

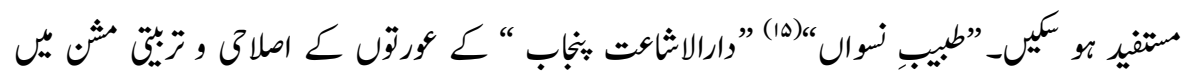

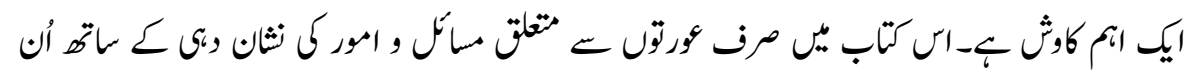

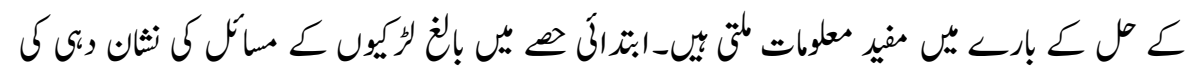

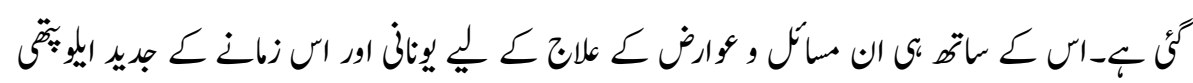

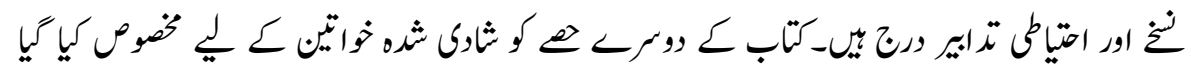

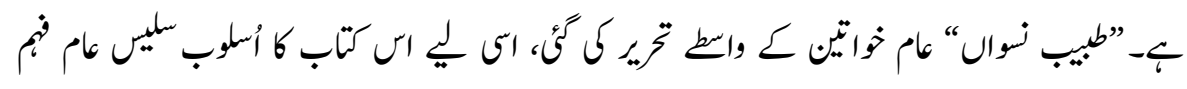


ISSN (Print): 2709-9636 | ISSN (Online): 2709-9644

Volume 2, 2021(Issue III, July to September)

اخذ تخيقي مجله

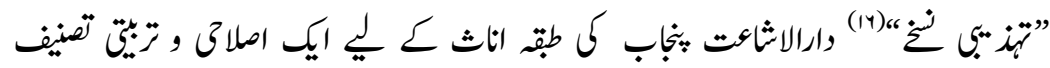

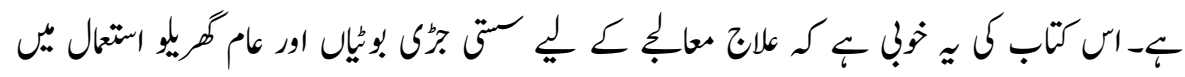

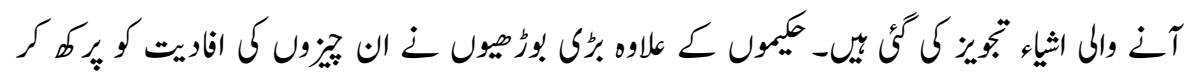

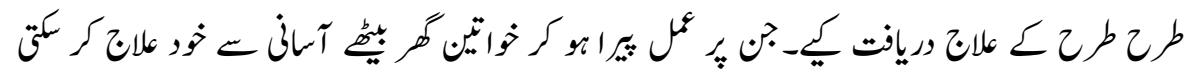

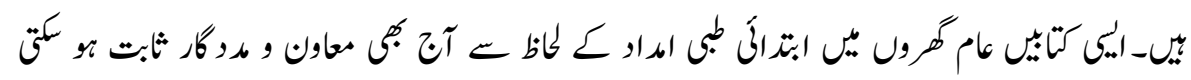

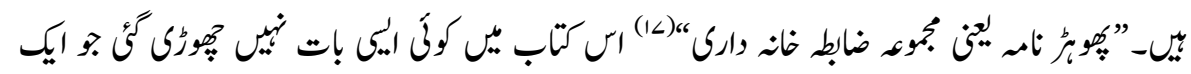

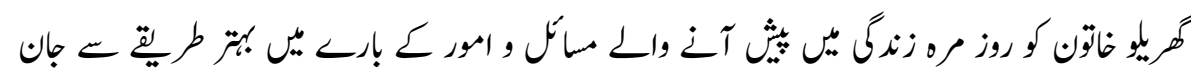

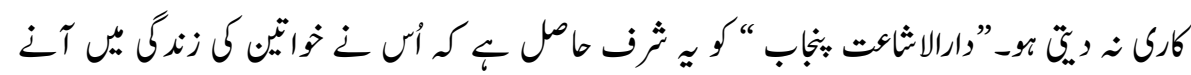

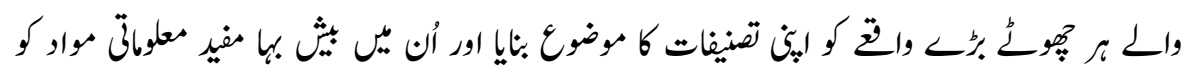

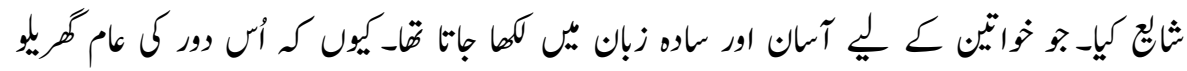

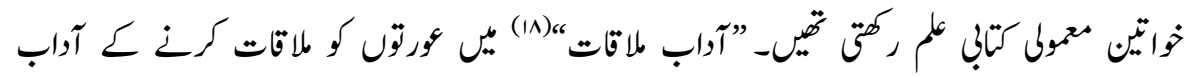

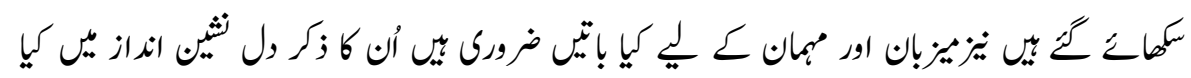

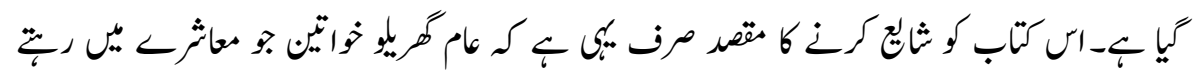

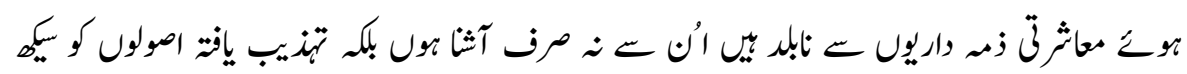

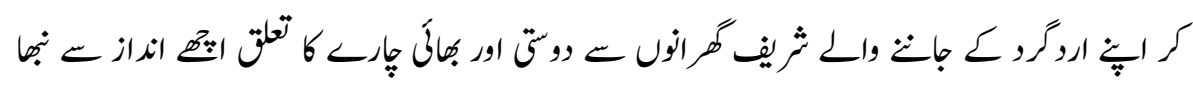

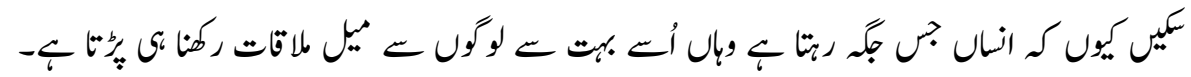

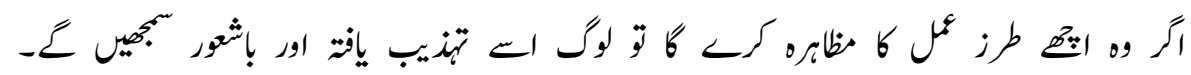

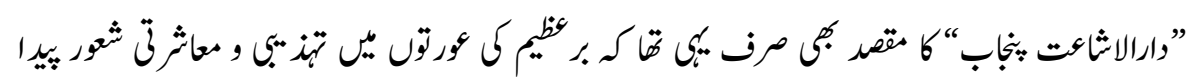
كيا بإبـ

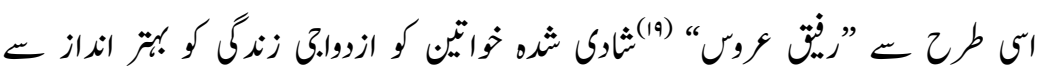

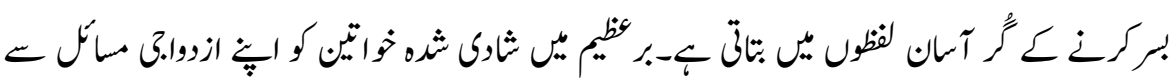

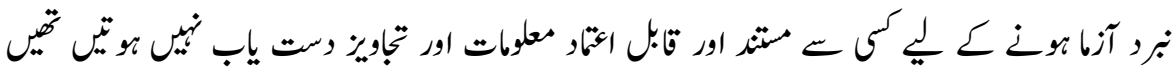

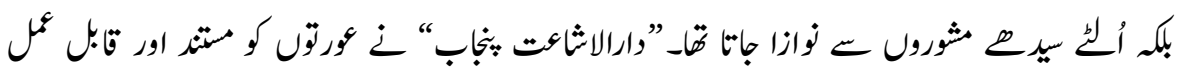




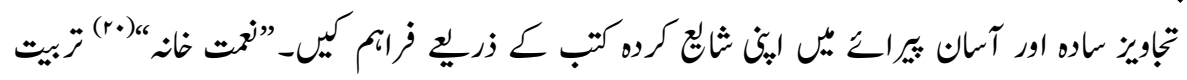

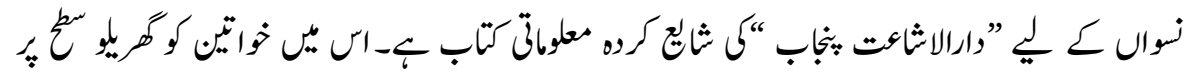

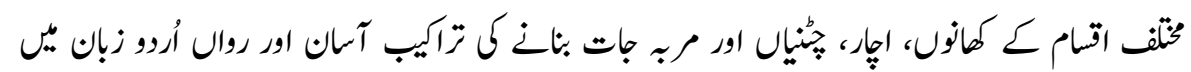

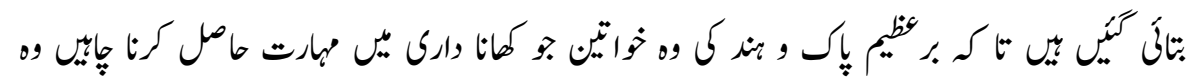

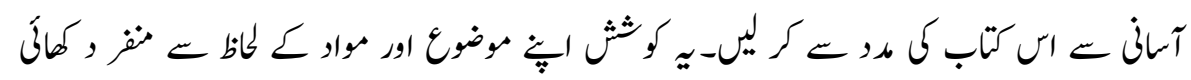

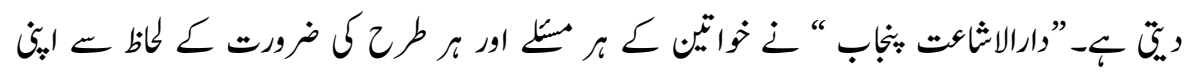

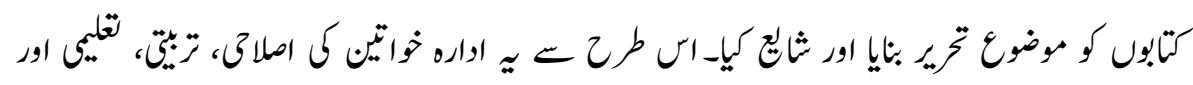

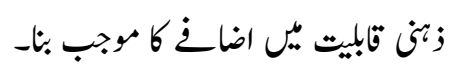

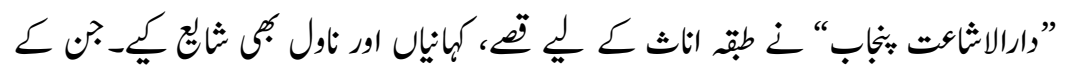

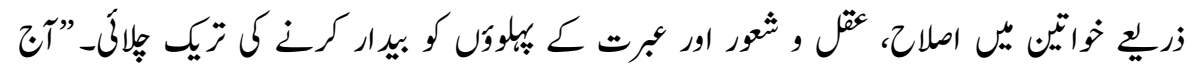

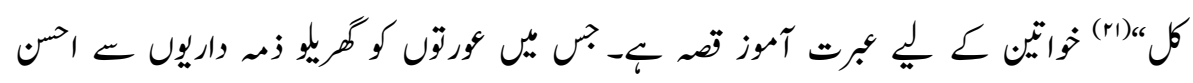

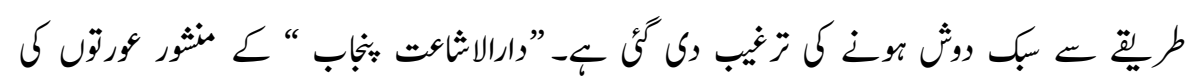

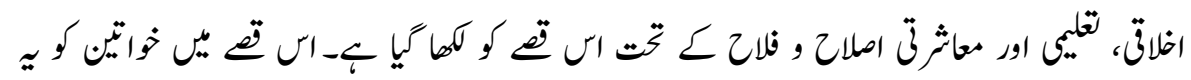

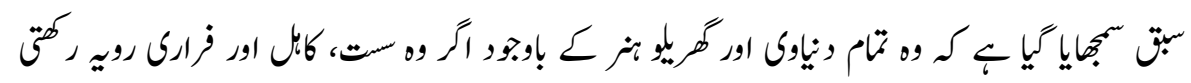

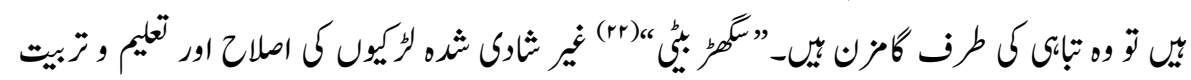

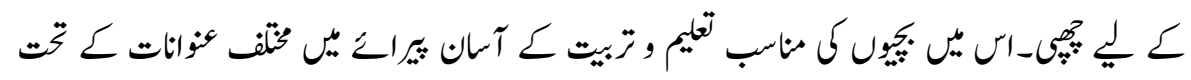

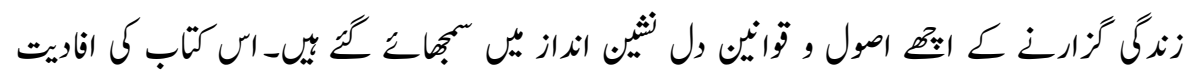

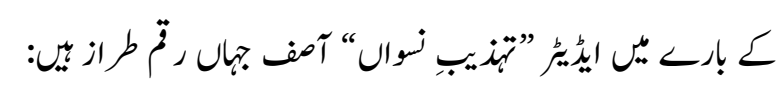

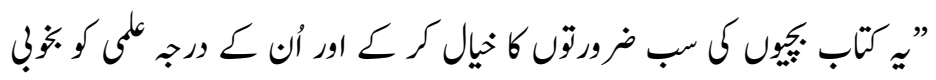

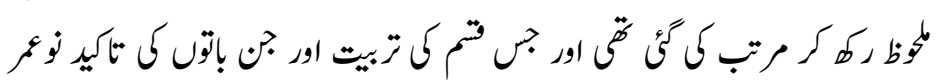

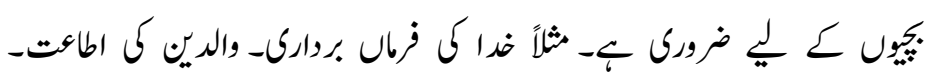

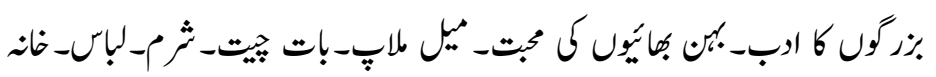

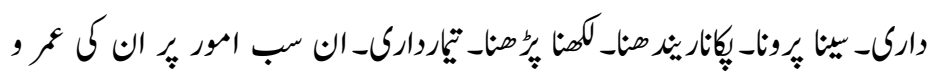


ISSN (Print): 2709-9636 | ISSN (Online): 2709-9644

Volume 2, 2021(Issue III, July to September)

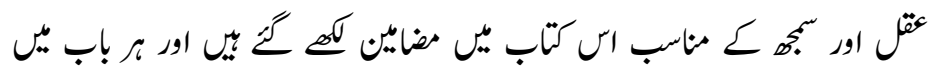

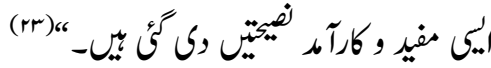

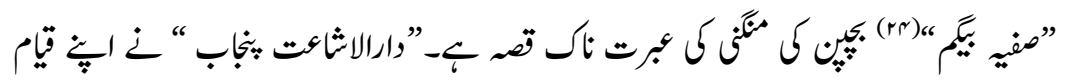

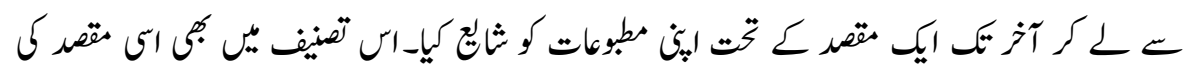

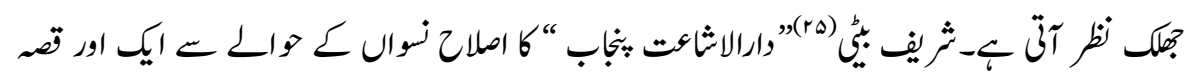

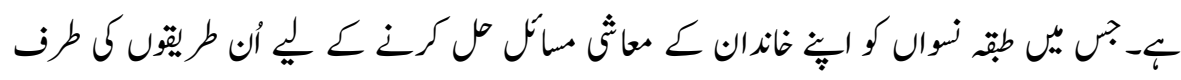

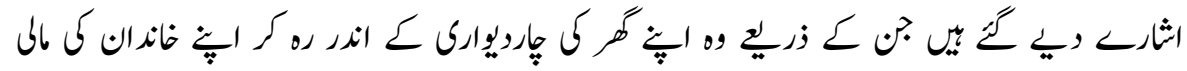

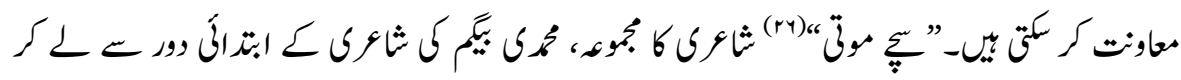

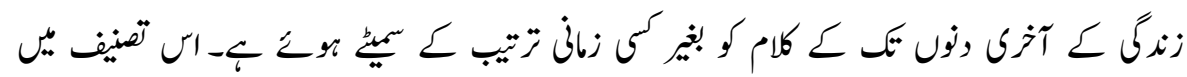

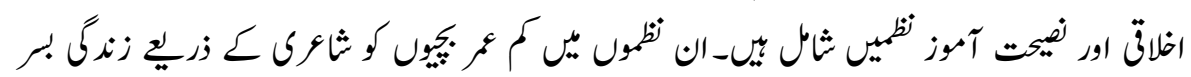

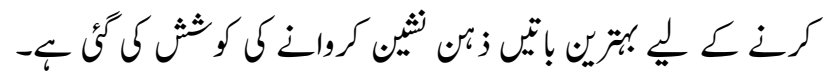

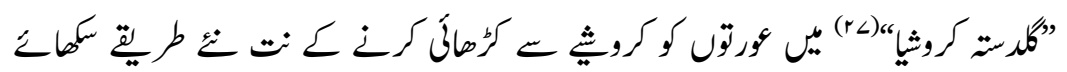

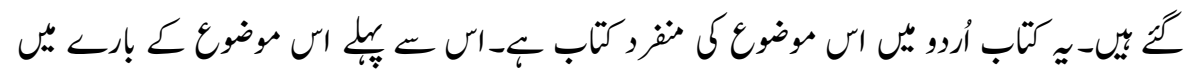

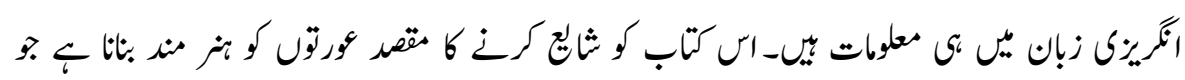

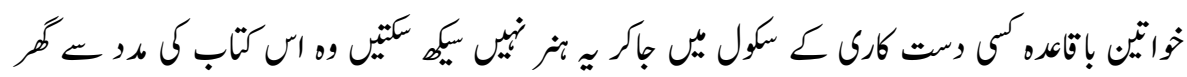

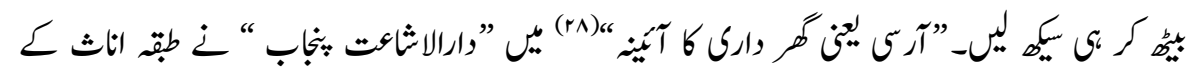

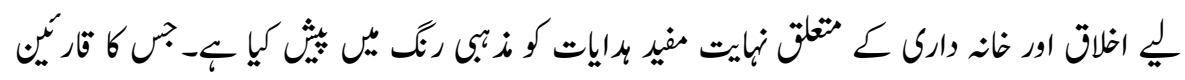

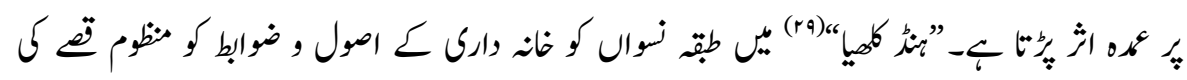

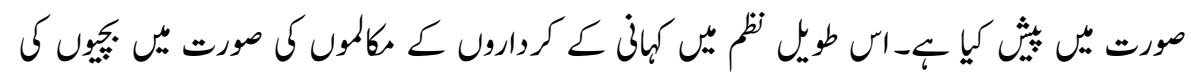

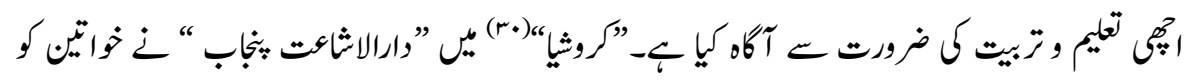

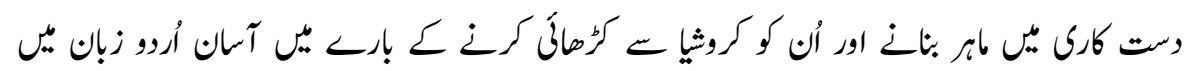

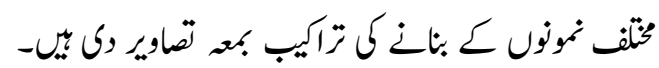

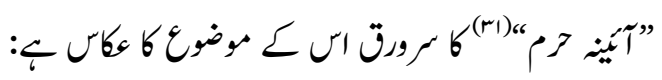




$$
\begin{aligned}
& \text { فَسَتَذْ كُرُوْْنَ مَا اََقُوْلُ لَكُمْ }
\end{aligned}
$$

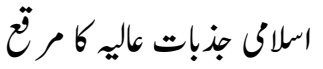

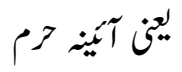

$$
\begin{aligned}
& \text { ? }
\end{aligned}
$$

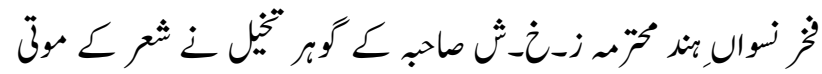

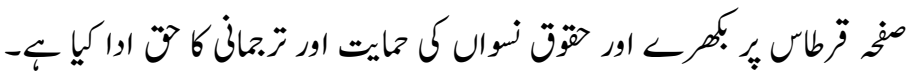

, $191<$

$$
\text { وارالاشاوت بنجاب }
$$

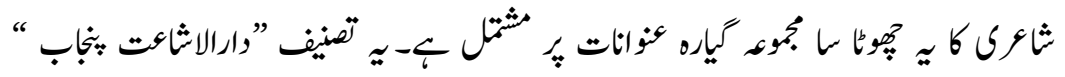

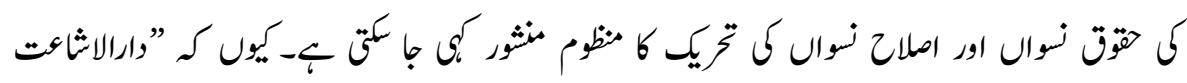

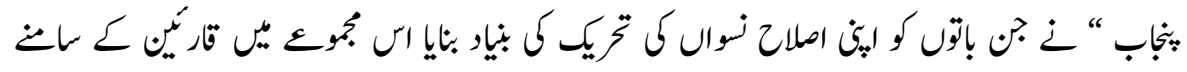

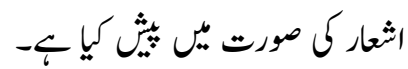

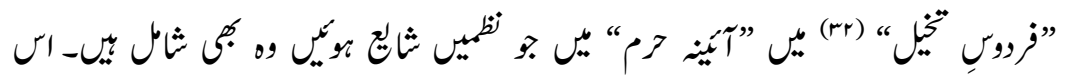

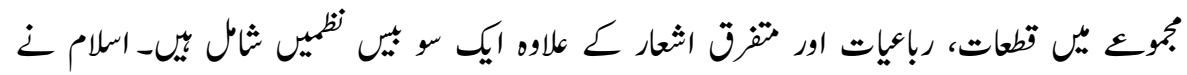

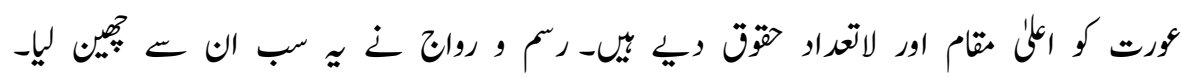

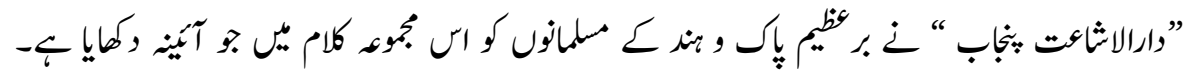

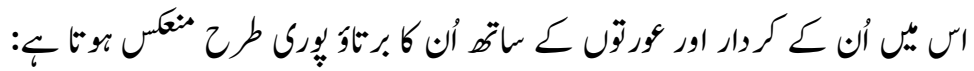

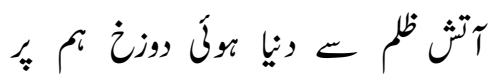

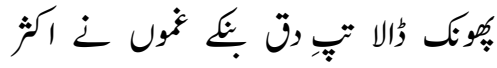

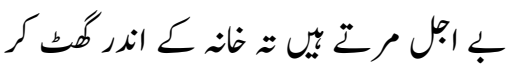

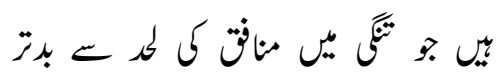

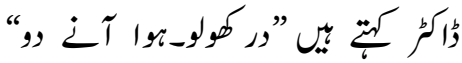

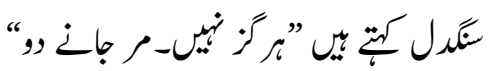




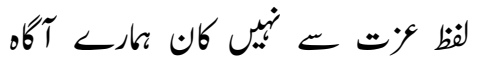

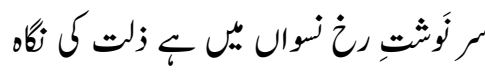

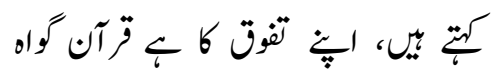

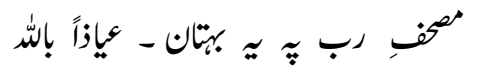

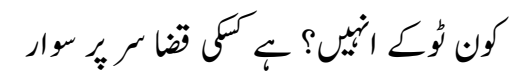

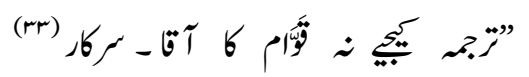

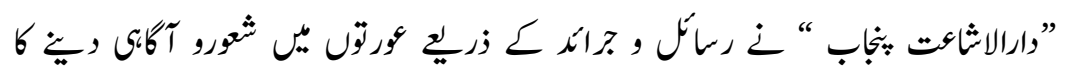

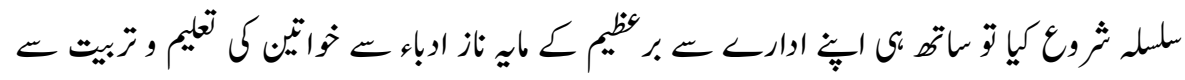

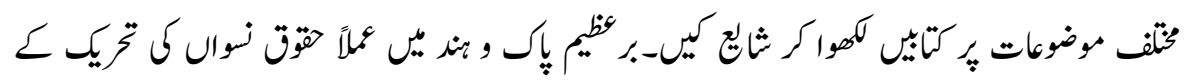

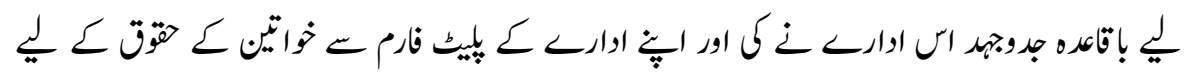
جاب وار آواز بلند كم-

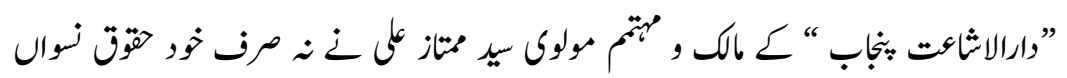

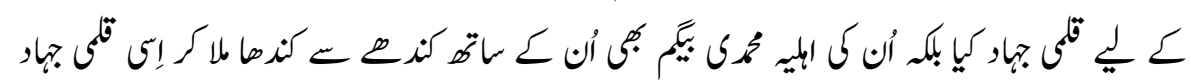

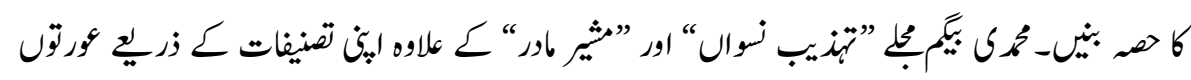

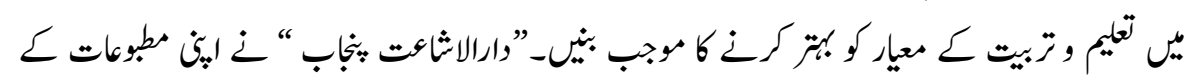

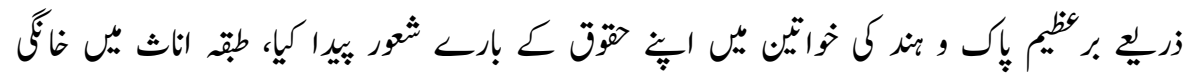

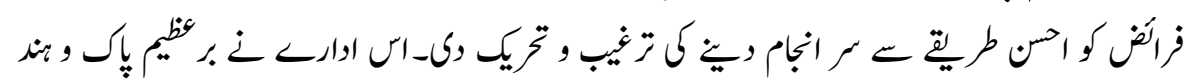

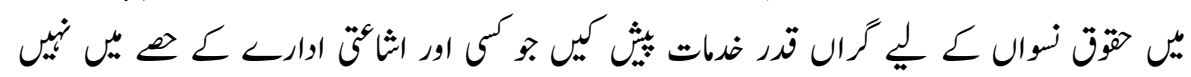

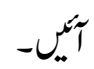

والد جات

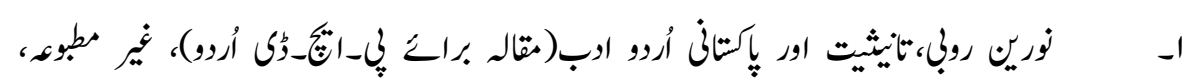

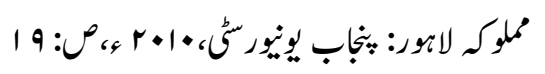

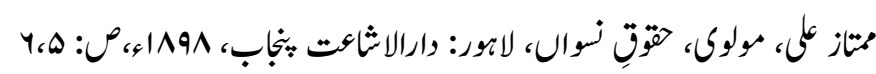


ISSN (Print): 2709-9636 | ISSN (Online): 2709-9644

Volume 2, 2021(Issue III, July to September)

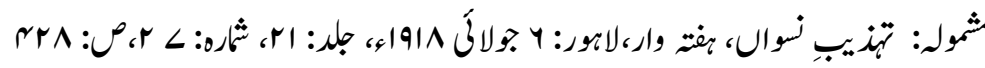

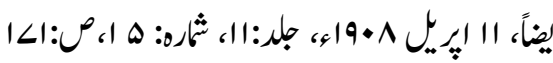

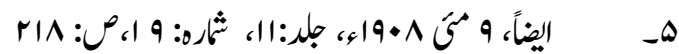

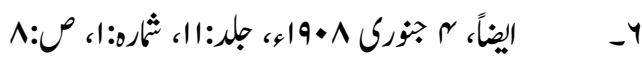

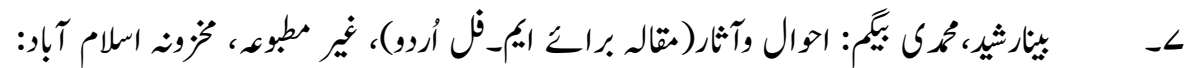

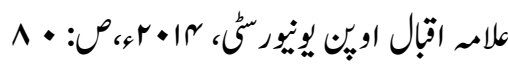

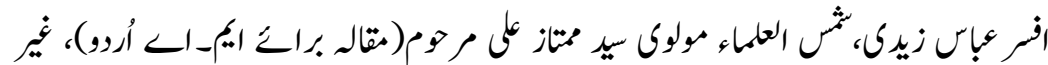

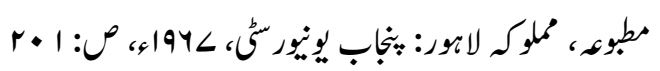

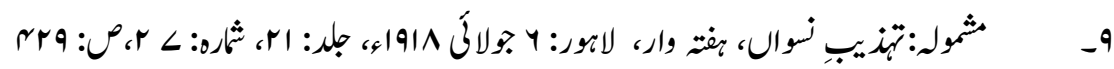

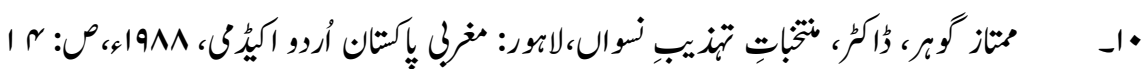

إيضاً،

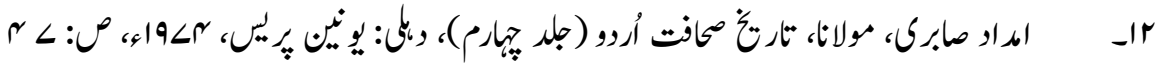

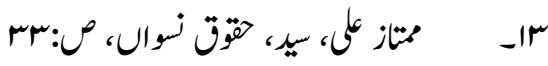

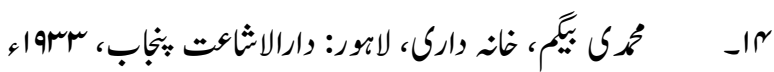

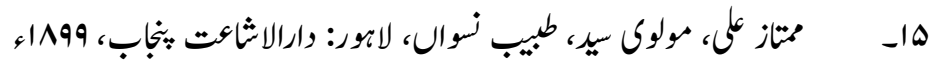

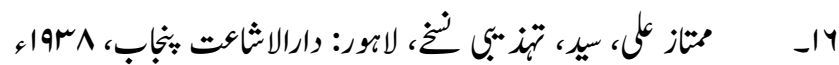

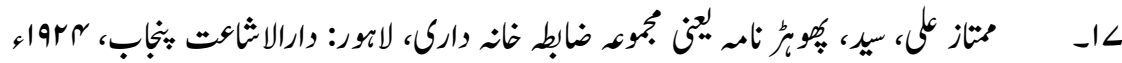

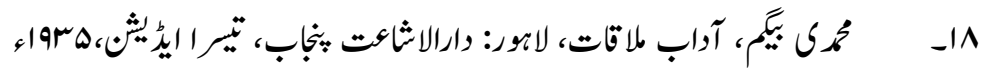

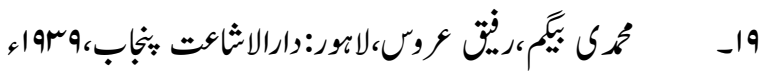

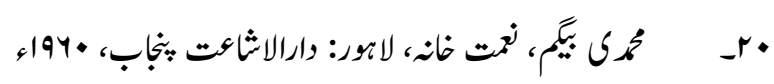

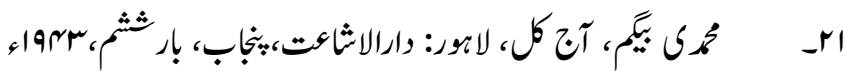

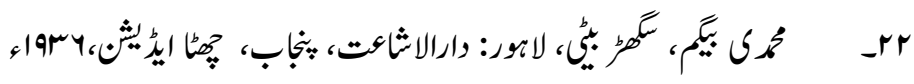

每 
ISSN (Print): 2709-9636 | ISSN (Online): 2709-9644

Volume 2, 2021(Issue III, July to September)

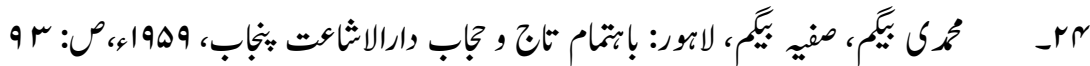

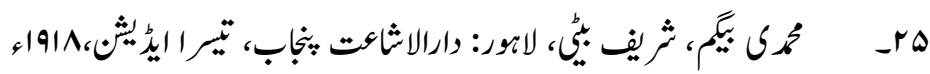

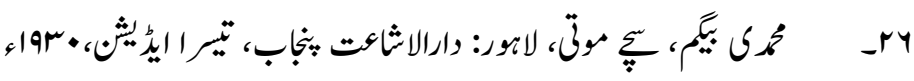

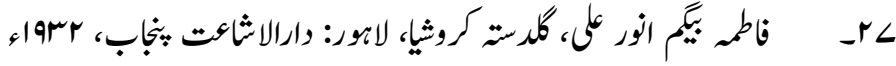

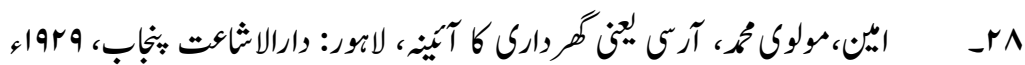

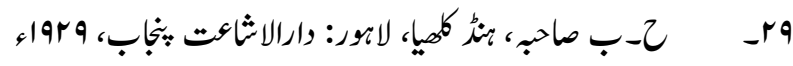

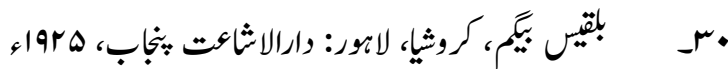

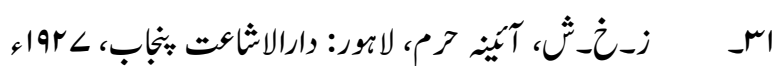

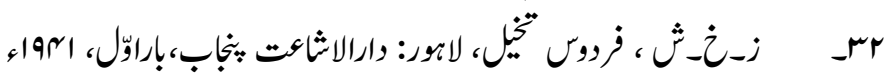

r 